energy intake was reduced by only $2.6 \%$. moments in a sleeping house the isolation Cutting out the carbohydrates led to a distinct increase in protein and fat consumption. On the alternative regimen mean daily calorie intake was reduced from 1,800 to about $1,200 \mathrm{kcal} /$ day, a reduction of $30 \%$. Mean weight losses after six weeks were $1.0 \mathrm{~kg}$ and $3.1 \mathrm{~kg}$ respectively. On the standard calorie-restricting diet serum cholesterol fell initially from $215 \mathrm{mg} / 100 \mathrm{ml}$ to $198 \mathrm{mg} / 100 \mathrm{ml}$ and then returned to the original level. On the low-carbohydrate diet the mean serum cholesterol level rose from $208 \mathrm{mg} / 100 \mathrm{ml}$ to $236 \mathrm{mg} / 100 \mathrm{ml}$ and in a few individuals to levels above $300 \mathrm{mg} / 100$ $\mathrm{ml}$. In general, the volunteers found that keeping to the low-carbohydrate diet was more difficult than keeping to the calorierestricting one, and the former regimen was estimated to be more expensive.

A critique of low-carbohydrate ketogenic weight reduction regimens has been published by the American Medical Association Council on Foods and Nutrition. ${ }^{2}$ I should regard two of the summary points as being most relevant:

"(3) The Council is deeply concerned about any diet that advocates an 'unlimited' intake of saturated fats and cholesterol-rich foods. In persons who respond to such a diet with an elevation of plasma lipids and an exaggerated alimentary hyperlipemia, the risk of coronary artery disease and other clinical manifestations or atherosclerosis may well be increased-particularly if the diet is maintained over a prolonged period.

“(4) Any grossly unbalanced diet, particularly one which interdicts the $45 \%$ of calories that is usually consumed as carbohydrates, is likely to induce some anorexia and weight reduction if the subject is willing to persevere in following such a bizarre regimen. However, it is unlikely that such a diet can provide a practicable basis for long-term weight reduction or maintenance, that is, a lifetime change in eating and exercise habits."

While a low-carbohydrate diet may be more acceptable to certain patients, such a diet will cause elevation of blood cholesterol in some people. If one is worried about cholesterol levels when planning a diet, it is prudent to limit foods high in cholesterol and saturated fat. Such a diet will still contain adequate amounts of fat-soluble vitamins. -I am, etc.,

J. I. MANN

Department of the Regius Professor of Medicine, Radcliffe Infirmary,

Oxford

1 Kouwenhovew, T., and Drijver, A., Voeding, 1973,

34. 180.
of the American Medical Association, 1973, 224, of the American Medical Association, 1973, 224, $180,285,1231,1415$.

\section{Cancer and the Patient}

SIR,-Professor G. W. Milton (27 October, p. 221) displays great understanding of the patient's reaction to a diagnosis of cancer. He also makes a point of enormous practical importance. In Britain we tend to examine the patient and then offer to see the accompanying relative, often not in the patient's presence. Frightened patients are thus effectively isolated from their most valuable source of support. At the back of their mind they may never quite believe that husband or wife has been entirely honest and is not concealing further bad news in an attempt to spare the patient greater distress. The loved one joins, as it were, life's conspiracy against the patient. In their darkest must be unbearable. But if the doctor discusses the situation with all concerned there can be no grounds for mistrust. Though this can be much more difficult, it is more humane.-I am, etc.,

Hammersmith Hospital,

\section{E. A. Macdonald} London $\mathbf{W} .12$

\section{F.D.P. Levels in Intravascular Haemolysis}

SIR,-Dr. S. D. Slater and his colleagues (1 September, p. 471) suggest that chronic haemolysis does not lead to intravascular coagulation in the absence of "other precipitating factors." This is true also in clinical cases of acute massive haemolysis, as shown by the normal levels of serum fibrinogen - fibrin degradation products (F.D.P.) and the absence of other signs of intravascular coagulation in sensitive Sardinian subjects following ingestion of fava beans. ${ }^{1}$ On the other hand, situations of acute haemolysis of comparable degree, such as the transfusion of incompatible blood, drowning haemoglobinaemia, and ingestion of strong acids, ${ }^{3}$ are accompanied by consumption of coagulation factors and increased F.D.P. levels. What, then, are the "precipitating factors" and why does intravascular coagulation occur in some cases and not in others?

Dr. E. N. Wardle (13 October, p. 111) is right in emphasizing the key role played by the state of functional activity of the convincingly demonstrated by the experimental findings of Rabiner and Friedman, who showed that intravascular coagulation followed the infusion of lysed red cells only after depression of the reticuloendothelial system by carbon or splenectomy. Therefore I think that the different findings in the acute attack of favism and in incompatible blood transfusion may be similarly explained by the presence of an intact reticuloendothelial system in the former and by its depression by shock in the latter. ${ }^{6}$

I cannot support the suggestion of $\mathrm{Dr}$. Wardle that impaired removal of fibrin by defective fibrinolysis plays a relevant role in conditioning the occurrence of intravascular coagulation after haemolytic anaemia. In unpublished observations on cases of favism the fibrinolytic activity was very depressed and yet there was no evidence of fibrin deposition and intravascular coagulation.-I am, etc.,

\section{P. M. MANNUCCI}

Haemophilia and Thrombosis Centre,

University of Milan,

Italy

Mannucci, P. M., Lobina, G. F., Caocci, L., and Dioguardi, N., Blood, 1969, 33, 207

Sack, E. S., and Nefa, O. M., Transfusion, 1970, Sack, 317 .

Riedler, G., Frick. P. G., and Straub, P. W Helvetica., Medica Acta, 1968, 34, 205.

4 Riedler, G., Straub, P. W., and Frick, P. G.

5 Rabiner, S. F., and Friedman, L. H., British Fournal of Haematology, 1968, 14, 105.

Hardway, R. M., et al., fournal of Trauma, 1964, 4,624 .

\section{Muscle Cramps during Maintenance Haemodialysis}

SIR,-May we have the privilege of replying briefly to the letter from Dr. G. R. D. Catto and others (3 November, p. 301)? reticuloendothelial system. This has been Helvetica Medica Acta, 1968, 34, 223.
With regard to their first point, we must disclaim any intention of suggesting that the mean inter-dialysis weight gain of 4-5 kg during isonatric dialysis (dialysate sodium = $145 \mathrm{mmol} / \mathrm{l}$.) was due mainly to the threeday interval between twice-weekly dialyses. On the basis of twice-weekly dialysis, the inter-dialysis weight gain almost doubles on isonatric dialysis compared with lowsodium dialysis. ${ }^{1}$ However, it is obvious that if our patients were receiving thrice-weekly dialysis the mean inter-dialysis weight gain would be less. Our range of weight change would, we agree, be unacceptable on low-sodium dialysis, but a much wider range of weight fluctuation is acceptable during isonatric dialysis. Our patients are advised to limit their weight gain to a maximum of $1 \mathrm{~kg}$ per day between dialyses. We reiterate that all the patients in Dundee, including those on home dialysis, tolerate well both their weight gain and the increased ultrafiltration required to maintain their ideal postdialysis weight. Indeed, those who remember pre-isonatric days react with dismay to any suggestion that they return to low-sodium dialysis with its attendant symptoms of "disequilibrium."

In fact, we have never advocated the use of isonatric dialysate for the sole and specific purpose of reducing cramps. The decrease in the incidence of cramps was one incidental benefit among others. ${ }^{2}$ Port et al. ${ }^{3}$ have independently demonstrated the benefit of "high-sodium" dialysate (149 $\mathrm{mmol} / \mathrm{l}$.) in reducing symptoms of disequilibrium and maintaining a more normal electroencephalographic pattern during an experimental single dialysis.

We should perhaps mention that some insight and acquired skill are required in regulating the increased rate of ultrafiltration for some patients. However, once established, the routine has proved entirely satisfactory, and isonatric dialysis has remained standard practice for all patients in Dundee, including those on home dialysis, over the past three years.-We are, etc.

W. K. STEWART LAURA W. FLEMING

Department of Medicine,

University of Dundee,

Dundee 1 Stewart, W. K., Fleming, L. W., and Manuel,
M. A., Proceedings of the European Dialysis and
Transplant Association, 1972, , 111.
2 Stewart, W. K., Fleming, L. W., and Manuel,
M. A., Lancet, 1972, 1. 1049.
3 Port, F. K., Johnson, W J., and Klass, D. W.,
Kidney International, 1973, 3, 327.

\section{Aid to Lumbar Puncture}

SIR,-In performing lumbar puncture it is advisable to use as fine a needle as possible. There are now a number of manufacturers who produce a 22-gauge disposable spinal needle. With such a fine needle there are problems both in introducing the needle through the skin and ligaments and in ensuring that the needle travels in the desired direction. There are numerous ways of overcoming these problems and the purpose of this letter is to describe an easy and convenient way of dealing with both introduction and direction of the spinal needle.

After the usual preparation an intravenous cannula of an appropriate size (I use a no. 1 Braunula) is inserted in the selected spinal interspace until it is well placed in the ligaments. The inner needle portion is with- 
drawn leaving the cannula in situ. The. spinal needle is then passed through the cannula and advanced to puncture the dura. The ready availability of disposable intravenous cannulae and spinal needles makes the above technique possible in most circumstances.-I am, etc.,

Department of Anaesthetics,

W. SNIPER Victoria Infirmary, Glasgow

\section{Raynaud's Disease and Systemic Sclerosis}

SIR,- - In your leading article on scleroderma (3 November, p. 249) it is stated that patients with primary Raynaud's disease "can be reassured that if the syndrome has lasted more than two years without evidence of scleroderma the chances of it developing are small, though not excluded." I think it is necessary to qualify this statement by reference to the sex differences in the interval between the onset of Raynaud's phenomenon and the development of the cutaneous and other changes found in systemic sclerosis.

Analysis of a personal series of 33 consecutive cases of systemic sclerosis has shown that the mean interval between the onset of Raynaud's phenomenon and the onset of scleroderma is shorter in males ( 0.9 years) than in females ( 5.2 years). This difference is even more strikingly shown in the following table.

\begin{tabular}{c|c|c|c}
\hline $\begin{array}{c}\text { Interval } \\
\text { (Years) }\end{array}$ & Male & Female & Total \\
\hline $0-2$ & 7 & 9 & 16 \\
\hline $3-4$ & 0 & 5 & 5 \\
$5-6$ & 0 & 6 & 6 \\
$7-8$ & 0 & 2 & 2 \\
$9-30$ & 0 & 4 & 4 \\
\hline & 7 & 26 & 33
\end{tabular}

Dichotomized as shown, $\mathrm{P}<0.01$.

It will be seen that the statement quoted above will apply to males but not to females. In systemic sclerosis it would appear that the disease process is speeded up in males. In observations over a five-year period three out of 10 males died $(30 \%)$ compared with six out of 41 females $(14 \%)$, and the mean interval from diagnosis of Raynaud's phenomenon to death was 10 years in males and 15.5 years in females. Though these figures are not statistically significant, they show a trend towards a poorer prognosis in males.

That females have a better endogenous defence mechanism in autoaggressive disease is also shown in systemic lupus erythematosus. ${ }^{1-I}$ am, etc.,

Department of Dermatology,

N. R. ROWELL General Infirmary,

1 Kellum, R. E., and Haserick, J. R., Archives of Internal Medicine, 1964, 113, 200

\section{Delayed Attacks of Malaria in Visitors to the Tropics}

SIR,-In answer to Professor T. Wilson's comments (20 October, p. 172) on my previous letter (22 September, p. 637), my reference to insufficient dosage of suppressive chloroquine referred not to the weekly dose of the suppressive drug, which need not exceed $300 \mathrm{mg}$ of base, but to the number of weeks when it should be taken. In the cases reported by Dr. Paul Horstmann (25 August, p. 440) the drug was taken for two weeks after the group's return to Denmark, while four weeks is the usual duration of suppression after leaving the malarious area. Though much reduced, malaria is still present in Turkey and the last probable exposure to infection could have been traced to one of the places visited in that country two weeks before the party's return. I do not think that there are any other points on which our views diverge.

I might add that in the U.S.A. $25 \%$ of cases of imported malaria (113 out of 452) seen in 1972, the majority of them due to Plasmodium vivax, showed an incubation period of over six months. ${ }^{1}$ In the United Kingdom the relevant figure for such delayed incubation period was $13 \%$ (16 out of 122 ) in $1971^{2}$ and $16 \%$ (49 out of 307) in 1972. ${ }^{3}$ - I am, etc.,

\section{J. BRUCE-CHWATT}

Ross Institute of Tropical Hygiene,

London W.C.1

1 Center for Disease Control, Malaria Surveillance Annual Summary for 1972. Atlanta, Georgia, W.S. Departiare, 1973 .

2 British Medical fournal, 1972, 3, 652.

1972. In preparation.

\section{Breast-feeding}

SIR,-While few medical workers doubt the biological superiority of breast-feeding, its acceptance by women must surely be hindered by public attitudes as much as by the apathy of those concerned with infant health. It is encouraging to read of the recent increase in the number of women breast-feeding their babies in Cheltenham Maternity Hospital (3 November, p. 299) as a result of staff enthusiasm. Nevertheless, this represents the situation at the time of discharge from hospital and one wonders how many of the $64 \%$ quoted continued to breast-feed at home.

Once outside hospital many women are reluctant to continue breast-feeding for several reasons. They are completely tied to their babies, particularly if feeding is "on demand." A bottle-fed baby can be left in the care of a grandparent or nanny, allowing the mother to resume part-time employment and giving her greater freedom in her social life. The loss of even one natural feed may be enough to upset the mother's ability to continue successfully, and the unrelieved breast engorgement can be distressing. For some women, breast-feeding takes much longer. Care of the breasts may have been so ritualized in hospital that the woman feels it is nearly as fiddly as preparing a bottle. Perhaps the overriding factor is the difficulty encountered when trying to breastfeed in public-for instance, on a train or in a restaurant-owing to the embarrassed reaction of onlookers.

In an age when most women are neither prepared nor able to remain continually at home nursing their babies, more attention should be paid to improving the public image of the nursing mother. Despite contemporary liberal attitudes towards sex, there is still a widespread notion that breastfeeding is embarrassing, indecent, and vulgar if it takes place anywhere except in the utmost privacy. Indeed, one patient told me recently that a female friend visiting her at home got up to go to another room when the patient began breast-feeding. Only by "popularizing" the image of the nursing mother and recognizing her needs outside her own home will the efforts of medical staff produce their greatest impact.-I am, etc.,

Roger Rot

SIR,-I have read with interest the paper by Dr. Peter Carson and others (27 October, p. 213) on exercise after myocardial infarction. It seems likely, from this and other studies, that the development of exercise routines would be of considerable value and could probably be a feasible proposition in district hospitals.

I should like to suggest that physiotherapists not only could, but should, and indeed already are involved in rehabilitation programmes of this nature. Physiotherapists are trained in all aspects of rehabilitation and their knowledge of physiology and pathology would seem to make them an obvious choice for the supervision of exercise in post-infarction patients.

If rehabilitation of these patients is to become routine in physiotherapy departments of district hospitals, it would be practical to involve physiotherapy staff from the outset. The availability of both physiotherapists and medical staff to supervise patients will probably vary considerably, but it is to be hoped that, in both cases, the larger centres at least will be able to provide staff for further studies.-I am, etc.

BRENDA M. SAMUELS Hon PRO G M. SAMUELS Chartered Society of Physiotherapy

Rehabilitation Centre, Southern General Hospital, Glasgow

\section{Battered Children}

SIR,-I refer to your leading article (13 October, p. 61), and quote again your passage quoted by the Evening Standard: "The family doctor's first and immediate responsibility is to refer the child to the nearest hospital . . . without delay, for delay may mean the death of the child." I had hoped O that an abler pen than mine would offer constructive criticism, but you have published none and the subject is important and still topical.

It has been said before that a family doctor is not merely a finger-post to the nearest hospital. At the least, he may know that the nearest is not the most suitable, or that at a given hospital injuries will be well cared for but extra-hospital implications will not easily be allowed into consciousness. At the best, the family doctor and his team may be able to do a safer and better job for the whole sick family than any other organization can.

In every case the family doctor has to consider his own knowledge of the child and family, his knowledge of local social services (official and voluntary), of neighbours, of the local N.S.P.C.C., possibly even of the police and magistrate's court, and of course of local paediatricians and hospitals. He can 